\title{
Violencias contra la mujer e intrafamiliar y responsabilidad civil por daño intrafamiliar en Colombia: a propósito de la sentencia SU-080 de 2020*
}

\author{
I Natalia Rueda**
}

Resumen: La Corte Constitucional colombiana reconoció abiertamente la posibilidad de que dentro de un proceso de familia donde se ventilen cuestiones de violencia de género se indemnice a la víctima, de manera que se garantice el derecho fundamental de la mujer de vivir libre de violencia y a ser reparada de manera integral. Esta histórica sentencia posibilita una mayor protección de las víctimas; sin embargo, presenta puntos críticos respecto de la protección de otros miembros de la familia posibles víctimas de maltrato o violencia intrafamiliar. Este comentario presenta dichos puntos y señala las posibilidades existentes en el derecho civil, para lograr la indemnización de los daños intrafamiliares.

Palabras Clave: violencia intrafamiliar, violencia de género, maltrato, daño intrafamiliar, responsabilidad civil.

* Fecha de recepción: 29 de marzo de 2020. Fecha de aceptación: 27 de abril de 2020.

Para citar el artículo: RuEdA. N., "Violencias contra la mujer e intrafamiliar y responsabilidad civil por daño intrafamiliar en Colombia: a propósito de la sentencia SU-080 de 2020", Revista de Derecho Privado, n. ${ }^{\circ} 39$, julio-diciembre 2020, 385-396, Dor: https://doi.org/10.18601/01234366.n39.15.

** Universidad Externado de Colombia, Bogotá, Colombia; docente investigadora. Doctora con mención cum laude y de International doctorate en Ciencias Jurídicas con énfasis en derecho privado, Università di Pisa, Pisa, Italia. Abogada, Universidad Externado de Colombia, Bogotá, Colombia. Contacto: natalia.rueda@uexternado.edu.co. Orcid: 0000-0002-0008-1897. 


\title{
Gender-based Violence, Domestic Violence and Civil Liability for Intra-Family Torts in Colombia
}

\begin{abstract}
The Colombian Constitutional Court recognized the compensation of intrafamily torts within a process where issues of gender violence are aired, to guarantee the fundamental right of women to live free of violence and to be compensated. This historic decision enables greater protection for victims; however, it presents critical points regarding the protection of other family members who may be victims of abuse or domestic violence. This work presents these points and highlights the possibilities existing in civil law, to achieve compensation for intra-family torts.
\end{abstract}

KEYWORDS: domestic violence, gender violence, abuse, intrafamily torts, civil liability.

Sumario: Introducción. I. Antecedentes de la sentencia SU-080 de 2020. II. Una lectura crítica de la decisión. A modo de conclusión. Bibliografía.

La disputa durará mientras los hombres y las mujeres no se reconozcan como semejantes

Simone de BeAuvoir ${ }^{1}$

\section{Introducción}

La violencia machista es un fenómeno ampliamente estudiado en distintas disciplinas $^{2} \mathrm{y}$, al mismo tiempo, aceptado, normalizado e incluso promovido en la sociedad ${ }^{3}$. Se trata, pues, de una práctica que no conoce fronteras de ningún tipo: ni la edad, ni el género, ni la profesión, ni el nivel cultural, educativo o socioeconómico, ni la nacionalidad. Además, es un fenómeno recurrente con independencia de las distintas

1 Beauvoir, S. DE., El segundo sexo, Ediciones Cátedra, Madrid, 13. a ed. en español, 2018, 813.

2 Para mencionar solo algunos ejemplos en la filosofía, la historia, la psicología, la sociología y el derecho, piénsese en Bourdieu, P., La domination masculine, Éditions du Seuil, Paris, 1998; FECI, S. y SCHETtini, L. (eds.), La violenza contro le donne nella storia: contesti, linguaggi, politiche del diritto (secoli XV-XXI), Storia delle donne e di genere; Plurale 8, Viella, Roma, 2017; HAN, B-C., Topología de la violencia, Herder, Barcelona, 5. a reimp., 2018; Irigaray, L., Speculum. De l'autre femme, Les éditions de Minuit, Paris, 1974; además del clásico BEauvorr, S. DE., El segundo sexo, Ediciones Cátedra, Madrid, 13. ' ed. en español, 2018.

3 De esto dan cuenta varios estudios de campo en relación con las prácticas de normalización de la violencia como manifestación del machismo radicado en la cultura. Véanse, entre otros, ARIZA, A. "Morir de amor. Una mirada a las violencias afectivas desde un enfoque de cultura ciudadana", en Eslava, A. (ed.), Lo mejor de las personas. Teoría, intervención y agenda de la cultura ciudadana, Alcaldía de Medellín, Medellín, 2019, 103-122; Rey Anacona, C. A. y Martínez Gómez, J. A., Violencia en el noviazgo. Evaluación, prevención e intervención de los malos tratos en parejas jóvenes, Manual Moderno, Bogotá, 2018; Saldarriaga, D. C. y Álvarez Cadavid, N., Mujeres víctimas de violencia intrafamiliar. Implementación de la Ley 1257 de 2008, Unaula, Medellín, 2019. 
épocas o culturas, aunque sí puede variar en relación con el recrudecimiento de ciertas expresiones violentas y, en ocasiones, con una mayor brutalidad en las agresiones contra las mujeres ${ }^{4}$. En este contexto, tampoco la familia se ha visto librada de esta práctica, por el contrario, el grupo familiar en no pocas ocasiones se convierte en un escenario donde la violencia se tolera, normaliza e, incluso, justifica con mayor facilidad, con el agravante de que la relación familiar puede fungir como excusa para una impunidad e inmunidad generalizadas, razón por la cual no es descabellado afirmar una prevalencia en la naturaleza familiar de la violencia contra las mujeres.

Dicha constatación conduce a una serie de confluencias que dificultan la valoración de la incidencia de dos problemas actuales y de extrema gravedad: la violencia de género y la violencia intrafamiliar. Esta confusión de fenómenos propicia una aproximación parcial tanto a la violencia de género como a la violencia intrafamiliar, pues no siempre que se presenta la una necesariamente se presenta la otra, cuestión que resulta coadyuvada por la falta de datos precisos, uniformes y confiables. Esta consideración suscita una reflexión crítica sobre la sentencia SU-080 de 2020 de la Corte Constitucional colombiana, en un conocido caso de violencia de pareja -de género-, donde se señaló la posibilidad de indemnizar a la mujer víctima de violencia con miras a garantizar su derecho a vivir libre de violencia y a ser reparada de forma integral, aunque la pretensión de reparación se solicitara en un proceso de divorcio o cesación de efectos civiles de matrimonio católico.

En ese sentido, el propósito de este escrito es el de analizar de manera crítica dicha decisión, a partir de la consideración de que se trata de una sentencia hito, pero cuyo alcance, bien sea porque se trata de una sentencia de tutela, bien sea porque el juez constitucional decidió restringir las condiciones para la reparación, puede resultar limitado con miras a la obtención de la reparación integral en un contexto en el que resulta imperativo reparar los daños intrafamiliares con independencia de la fuente que los origine. Así las cosas, se mostrarán los aspectos críticos de la decisión, para sugerir algunos elementos que pueden ilustrar la eventual aplicación de las reglas de responsabilidad civil por daños intrafamiliares. Se presentará una síntesis del caso y la decisión, para luego hacer una lectura crítica de sus consideraciones y fundamentos, a partir de algunas fuentes relevantes en relación con la reparación de los daños intrafamiliares, las violencias, de género e intrafamiliar. Sin más preámbulos se pasa al estudio del problema que nos ocupa.

\section{Antecedentes de la sentencia SU-080 de 2020}

El caso que dio lugar a la sentencia en comento se originó en un proceso de cesación de efectos civiles de matrimonio católico y se puede resumir así:

4 Feci, S. y Schettini, L., "Storia e uso pubblico della violenza contro le donne”, en ID. (eds.), $L a$ violenza contro le donne nella storia: contesti, linguaggi, politiche del diritto (secoli XV-XXI), Storia delle donne e di genere; Plurale 8, Viella, Roma, 2017, 8. 
La demandante inició un proceso de cesación de efectos civiles de matrimonio católico contra su cónyuge con base en las causales 2, 3 y 8 del artículo 154 c. c. y con fundamento en ello solicitó que se condenara al demandado al pago de alimentos a título de reparación. Esta pretensión se explica, por cuanto refiere la sentencia, en que, en el criterio de la parte demandante, en el momento en que se inició el proceso no contaba con un mecanismo distinto para obtener la reparación del daño padecido en virtud de la violencia. A lo largo de todo el proceso, la demandante insiste en ello con base en que los alimentos reconocidos en contra del cónyuge culpable y que, por tanto, resulta vencido en el proceso de divorcio-cesación de efectos civiles de matrimonio católico constituyen una sanción ${ }^{5}$.

Tanto en primera como en segunda instancias, con algunas diferencias, los jueces declaran probadas las causales, pero no ordenan el pago de la obligación alimentaria por falta de la prueba de la necesidad de la demandante. Estas decisiones bien pueden ser criticadas por no haber considerado la posibilidad de reconocer el daño padecido por la víctima de la violencia, por la estrecha visión de la obligación de reparar los daños; pero mal podrían criticarse por el fundamento de la decisión, pues en este caso, y no obstante considerar que no tenía otra vía para reclamar los perjuicios, la pretensión de obtener el reconocimiento de la obligación alimentaria a título de reparación no encuentra respaldo en el sistema jurídico colombiano.

En virtud de esta negativa, la parte demandante interpone una acción de tutela contra providencia judicial que conoce la Corte Suprema de Justicia, con miras a obtener la protección de su derecho fundamental a vivir libre de violencia, discriminación de género y violencia intrafamiliar. En dicho proceso, la Sala de Casación Civil $^{6}$ decide conceder el amparo, ordenando al tribunal competente que deje sin efectos la sentencia y falle nuevamente con fundamento en sus consideraciones ${ }^{7}$. En segunda instancia, la Sala de Casación Laboral ${ }^{8}$ revocó el fallo, negando la tutela, pero admitiendo la posibilidad de que la demandante acudiera a un proceso de responsabilidad civil para obtener la indemnización de los perjuicios sufridos. Valga anotar que ninguna de las dos salas pone en duda la posibilidad de indemnizar los perjuicios intrafamiliares. Lo que sí produce perplejidad de la decisión de la Sala de

5 Esta lectura de la obligación alimentaria no se comparte, por cuanto el fundamento de dicha obligación está en la solidaridad; si ello no fuera así, dicha obligación se ordenaría siempre y en cualquier circunstancia en que se declare la culpabilidad del cónyuge, cosa que no ocurre, pues para su reconocimiento es necesario que se verifique la configuración de los demás requisitos (necesidad del alimentado y capacidad del alimentante). Atribuirle este carácter sancionatorio podría conducir a un envilecimiento de la obligación y a desconocer situaciones en las que, pese a la declaratoria de culpabilidad, no media necesariamente una conducta reprochable que deba ser sancionada. Piénsese, por ejemplo, en el caso del divorcio por mutuo acuerdo motivado por la simple falta de interés en continuar la relación.

6 CSJ, cas. civ., 25 de julio de 2017, ref. stc10829-2017.

7 Para una reflexión sobre esta sentencia, pero también sobre la justificación de la reparación de los daños intrafamiliares, con respaldo en fuentes normativas nacionales, permítase el reenvío a RUEDA, N., "La violencia intrafamiliar como fuente de daño resarcible en Colombia", Revista de la Facultad de Derecho y Ciencias Políticas 48, n. ${ }^{\circ}$ 128, 2018, 193-217. 
Casación Laboral es la pretensión de que la víctima de un daño intrafamiliar deba emprender un proceso adicional, con todos los costos asociados a ello -económicos, procesales y de tipo emocional-. Esta visión constituye una violación del principio de economía procesal, pero además comporta una revictimización inaceptable en nuestro sistema constitucional.

En revisión, la sentencia SU-080 de 2020 de la Corte Constitucional revocó la decisión de segunda instancia, confirmó parcialmente la sentencia de primera instancia "en el entendido de que se protege el derecho fundamental de la actora a vivir libre de violencia de género, a ser reparada, a no ser revictimizada y a una decisión de la Administración de Justicia dentro de un plazo razonable". Además, ordenó al tribunal que decidió sobre la cesación de efectos civiles disponer "la apertura de un incidente de reparación integral en el que se especifiquen y tasen los perjuicios sufridos por la víctima".

\section{Una lectura crítica de la decisión}

Sea este el momento de señalar que esta es una decisión histórica en materia de violencia contra la mujer (que no necesariamente en materia de género) ${ }^{9}$, aunque ello no implique que esté libre de críticas. Ciertamente, es innegable la preocupación del juez constitucional por concretar la protección a la mujer víctima de violencia por parte de su cónyuge. Al respecto es importante hacer notar que el hecho de que quien cometa las agresiones sea una persona con la cual la víctima está unida por lazos afectivos, además de jurídicos, implica una mayor gravedad de la conducta y de sus consecuencias lesivas.

En primer lugar, porque del compañero afectivo con quien se ha decidido emprender un proyecto de vida en común se espera un comportamiento respetuoso, de colaboración, de solidaridad. Pero el vínculo familiar tiene además unos efectos amplificadores del daño, bien sea porque la víctima está obligada a vivir con el recuerdo permanente de la agresión, a convivir con su agresor y, por ende, a la posible reiteración de las agresiones; bien porque la víctima está sometida a temores que limitan su capacidad de reacción para, por ejemplo, buscar ayuda o denunciar al agresor, como el temor a perder ventajas derivadas de la convivencia o la incapacidad para proveer a su subsistencia o la de sus hijos, bien porque el afecto o la relación pueden condicionar a una mayor tolerancia y normalización de la violencia ${ }^{10}$, o bien por la influencia

9 Al respecto, valga precisar que la reducción de la violencia de género a la violencia contra la mujer es un error e invisibiliza otras víctimas de la violencia que tiene como base estereotipos de género. En ese sentido, el género es una categoría más amplia y que en relación con la violencia responde al hecho de que la víctima no atienda a los cánones estereotípicos de género; en ese sentido toda la población LGBTI u hombres no dominantes también pueden ser víctimas de violencia de género, cfr. Feci, S. y Schettini, L., "Storia e uso pubblico della violenza contro le donne”, cit., 13.

10 RuEda, N., La responsabilidad civil en el ejercicio de la parentalidad. Un estudio comparado entre Italia y Colombia, Universidad Externado de Colombia, Bogotá, 2020, 153 ss. y 281 ss., en prensa. 
que los mitos del amor romántico ejercen sobre las mujeres como un factor de riesgo para padecer la violencia machista ${ }^{11}$.

En medio de la preocupación por conceder protección a la mujer víctima de violencia de género, la Corte Constitucional constata un aparente déficit de protección en relación con el acceso a la administración de justicia y a una reparación integral efectiva de todos los daños padecidos. Dicho déficit consistiría, al decir de la Corte, en la falta de un recurso judicial efectivo para que la mujer víctima de violencia de género pueda acceder a la reparación integral. Sin embargo, esto es parcialmente cierto, pues valga señalar que, como se verá, la reparación de los perjuicios en las relaciones de familia es perfectamente factible, pese a la resistencia y omisión de los jueces.

Así las cosas, conviene en este punto recordar que violencia de género y violencia intrafamiliar no necesariamente coinciden; además, no es de recibo la conclusión según la cual las víctimas de violencia intrafamiliar no cuentan con mecanismos de acceso a la reparación integral. Lo que puede ocurrir, más bien, es que nuestros operadores jurídicos no interpretan correctamente la legislación relevante a la luz de los principios constitucionales. Es bajo esta óptica como la sentencia de la Corte Constitucional toma relevancia, pues pone en un primer plano la obligación de garantizar una protección efectiva de los derechos de las mujeres víctimas de violencia de género, y de las víctimas de violencia intrafamiliar (cualquiera que sea el origen de la violencia, habría que agregar necesariamente).

Para precisar la observación previa, es necesario afirmar que desde el derecho civil y de familia no es posible aceptar la afirmación según la cual no existe un remedio efectivo para que la víctima de cualquier daño en el marco de las relaciones familiares pueda acceder a la reparación. Esto porque en nuestro sistema jurídico rige el neminem laedere, que, en cuanto principio, irradia todo el ordenamiento y obliga a la reparación integral de todo daño. Dicho principio encuentra su consagración normativa en los artículos 2341 c. c. (que no fue considerado por la Corte en la decisión) y 16 de la Ley 446 de $1998^{[12]}$. Ello implica que la atribución de la responsabilidad civil depende de la comprobación de un daño antijurídico que en el caso de la violencia se puede concretar en una lesión a la integridad psicofísica de la víctima (esta lectura permite reconocer a las víctimas de cualquier tipo de violencia, bien sea física, psicológica, sexual o económica). Bajo esta lógica, la pretensión de exigir, como pareciera haber sucedido en alguna de las etapas de este proceso, que la víctima de violencia de género o intrafamiliar denuncie penalmente a su agresor para reconocer su derecho a la reparación integral, debiéndose iniciar un proceso

11 Cfr. Ariza, A. "Morir de amor. Una mirada a las violencias afectivas desde un enfoque de cultura ciudadana", cit.; y CRUZ del CASTILlo, C., "El amor romántico, los estereotipos de género y su relación con la violencia de pareja”, Aportaciones a la psicología social, iv, 2018, 459-474.

12 Para un estudio sobre este principio, véase SANDOvaL, D., "Reparación integral y responsabilidad civil: el concepto de reparación integral y su vigencia en los daños extrapatrimoniales a la persona como garantía de los derechos de las víctimas", Revista de Derecho Privado, Universidad Externado de Colombia, n. ${ }^{\circ} 25,2013,235-271$. 
paralelo o posterior, constituye una revictimización que estaría proscrita por nuestro sistema constitucional.

Tampoco es de recibo la idea según la cual el proceso de familia es ajeno a la imputación de responsabilidad civil y, por ende, al reconocimiento de perjuicios susceptibles de reparación. Para ello, baste pensar en la posibilidad que tiene el juez que conoce de la nulidad de matrimonio cuando ha mediado la mala fe de uno de los cónyuges en relación con la configuración de una posible causal de nulidad, de condenar al "pago de los perjuicios a cargo del cónyuge que por su culpa hubiere dado lugar a la nulidad del vínculo, a favor del otro, si este lo hubiere solicitado" (art. 389 num. 5 c. g. p., previsto en términos idénticos por el derogado art. 443 c. p. c.). Además, el artículo 148 c. c. señala como uno de los efectos de la nulidad del matrimonio que, "en caso de mala fe en alguno de los contrayentes, tendrá este [el contrayente en mala fe] obligación de indemnizar al otro todos los perjuicios que le haya ocasionado, estimados con juramento".

Esto implica que nuestro ordenamiento jurídico desde mucho antes de que se configuraran los supuestos de hecho que dieron lugar a este caso, tanto desde el punto de vista sustancial como procesal, prevé la posibilidad de que en un proceso de familia se discuta la responsabilidad de uno de los miembros de la pareja y, en consecuencia, se ordene el pago de la indemnización de los perjuicios dentro de la misma sentencia que ponga fin al proceso de familia ${ }^{13}$. Problema distinto es el de determinar los motivos para que ello no se diera, lo cual puede obedecer a una tácita inmunidad de los miembros de la familia en materia de responsabilidad civil ${ }^{14}$.

Ahora bien: la Corte Constitucional, omitiendo estos elementos, admitió que es necesario conceder una protección efectiva a la demandante, cuyo fundamento es la Convención Interamericana para Prevenir, Sancionar y Erradicar la Violencia contra

13 Véase en relación con este supuesto Albarracín Cogollo, A., "La reparación de los perjuicios ocasionados por el divorcio en la legislación colombiana”, Temas Socio-Jurídicos, vol. 30, n. . 62, 2012, 195 206; y Gómez CHíQuiza, M. E., "El resarcimiento de perjuicios causados en las relaciones de familia: una breve mirada desde la sociología y el derecho", Revista nuevos paradigmas de las ciencias sociales latinoamericanas, vol. 9 , n. ${ }^{\circ}$ 8, disponible en [www.ilae.edu.co/Ilae_OjsRev/index.php/NPvol-vIINro14/article/view/277]. Como si esto no bastara, entre otros ejemplos expresos de reconocimiento de la posibilidad de obtener el pago por los perjuicios que un familiar cause a otro, está el caso de la falsa representación de la paternidad, que ocurre cuando la mujer consiente en la configuración de la presunción de paternidad o atribuye la misma a sabiendas de que el presunto padre no es el padre biológico (art. 224 c. c.). En este caso, los daños se pueden causar tanto al padre biológico, como al presunto padre y al hijo. También en el ámbito de las relaciones paternofiliales, la CSJ, Cas. civ., 19 de octubre de 2017, ref. sTc16969-2017 reconoce la necesidad de que el falso padre que reconoce a una persona como su hijo, y con posterioridad a la crisis de la pareja pretende la impugnación de dicho reconocimiento, indemnice al hijo por los daños no patrimoniales que dicha conducta pueda causar. Este último caso está descrito por la doctrina como reconocimiento por complacencia, aunque es más preciso denominarlo reconocimiento conscientemente falso. Para un análisis más detenido de este tipo de daño, véase RuEDA, N., La responsabilidad civil en el ejercicio de la parentalidad, cit., 377 ss.

14 La regla de la inmunidad se entiende como la "exención del individuo del derecho común que vale para todos los ciudadanos (para nuestros fines, exención del derecho privado común), en virtud de la clase social o de la función o de la condición o del estado o de la cualidad de la persona [en este caso, la relación familiar]": Rescigno, P., "Immunità e privilegio", Rivista di diritto civile, I, 1961, 416. 
la Mujer, conocida también como la "Convención de Belem do Pará". Sin embargo, decir que el fundamento de la reparación es este y no el principio general de reparación integral constituye un artificio que podría terminar desconociendo situaciones de violencia intrafamiliar que no necesariamente están mediadas por la categoría del género.

Ciertamente, aplicar el enfoque de género y ordenar que todo funcionario en la toma de decisiones lo considere para evitar la perpetuación de estereotipos ${ }^{15}$ constituye una de las más importantes innovaciones de la Corte Constitucional, pues el enfoque diferencial de género aplicado a las actuaciones judiciales y administrativas contribuye, sin lugar a duda, a romper con visiones estereotipadas de la mujer y de la familia. Sin embargo, reducir todo análisis de la violencia a la cuestión de género y, en particular, a la violencia contra la mujer en casos en que en la familia hay pluralidad de víctimas puede conducir a un déficit de protección respecto de los sujetos que no estarían cobijados por la Convención de Belem do Pará en relación con la posibilidad de exigir medidas reparadoras. En este caso, por ejemplo, nada se dice en relación con los daños que pudieron haber padecido los hijos de la pareja y, en consecuencia, tampoco se dice nada en relación con su reparación, no obstante las pruebas en el proceso dieran cuenta también del maltrato hacia aquellos.

Por ello se afirma que la sentencia marca un hito en materia de violencia de género, lo cual sin duda es de la mayor relevancia; sin embargo, no resulta muy clara la decisión en su parte resolutiva, pues según la Corte el problema central es la violencia de género, pero, por ejemplo, en el exhorto, invita al Congreso a legislar en materia de violencia intrafamiliar, con lo cual es legítimo pensar que una aplicación del principio general de reparación en lugar de una referencia a la Convención de Belem do Pará como fundamento de responsabilidad civil habría sido más adecuada para orientar la decisión, por cuanto ese instrumento internacional resulta más restrictivo para garantizar los derechos de las víctimas de violencia intrafamiliar.

Es decir, el enfoque de género es, sin lugar a duda, esencial para la comprensión del fenómeno de la violencia contra la mujer, es una clave de interpretación esencial para entender las raíces históricas y culturales que han condicionado su existencia, prolongación en el tiempo, tolerancia y difusión, así como la brutalidad de las agresiones contra las mujeres, como una forma de perpetuación de un modelo basado en la desigualdad y en la jerarquía. Pero siendo una de las múltiples claves de lectura, debe dialogar con otras, como la violencia intrafamiliar, para garantizar la mayor y mejor protección posible. Esta decisión es un muy buen primer paso hacia la erradicación de la violencia contra la mujer, pero se queda corta en relación con la violencia intrafamiliar, de la cual habría podido decir mucho, pues en este caso, de lo que se puede ver en relación con las pruebas, también se comprobó una serie de conductas de maltrato hacia los hijos que bien habrían podido encontrar reproche y, por tanto, ser reparadas en la medida en que son también constitutivas de daño y fueron ventiladas a lo largo del proceso. 
En fin, en virtud de sus propias consideraciones, la Corte Constitucional decide exhortar al Congreso de la República a que "regule ampliamente el derecho fundamental a acceder a una reparación integral en los casos de violencia intrafamiliar, por medio de un mecanismo judicial justo y eficaz que respete los parámetros de debido proceso, plazo razonable y prohibición de revictimización”. En relación con esto, sería interesante que el legislador, si decide intervenir, no se detuviera solo en las conductas relativas a la violencia intrafamiliar, pues en la familia son muchas y variadas las hipótesis de daño, muchas de las cuales tienen lugar en contra de los hijos menores o de los adultos mayores, casos en los cuales se puede asistir a una violación sistemática de derechos fundamentales de sujetos de especial protección constitucional, sin que los jueces o los operadores jurídicos consideren la posibilidad de reparar esos daños en virtud del principio general de reparación. Todo bajo el entendido de que la intervención del legislador debería estar dirigida a precisar los mecanismos procesales para que el juez de familia pueda decidir sobre la eventual responsabilidad civil por daños intrafamiliares, aun al margen de la existencia de otro proceso de familia (de manera que, por ejemplo, se puedan reparar los daños por violencia intrafamiliar cuando esta se atienda por vía administrativa, o cuando los daños ocurran en la unión marital de hecho, donde no hay lugar a alegar causales para determinar la culpabilidad de uno de los miembros de la pareja en la ruptura de la relación).

Sin embargo, en criterio de quien escribe, nada impide que la reparación integral de los perjuicios sea una pretensión más de la demanda en los procesos de familia, pues se dan los supuestos para la acumulación de pretensiones ${ }^{16}$. Ello debe ser así, pues teniendo una jurisdicción especializada en derecho de familia y existiendo un vínculo indisoluble entre los hechos que dan lugar a los daños intrafamiliares y los hechos de la demanda en el proceso de familia, no es de recibo la tesis de la Sala de Casación Laboral, según la cual debe decidirse sobre ello en un proceso judicial distinto. Mientras ocurre esto, la decisión de que se resuelva mediante el incidente de reparación integral es completamente plausible, bajo el entendido de que se trate, como en el caso que da lugar a la sentencia SU-080 de 2020, de determinar la responsabilidad y condenar al pago de los perjuicios luego de que el proceso de familia haya concluido con sentencia en firme.

\section{A modo de conclusión}

Partiendo de la premisa de que la violencia intrafamiliar causa daños antijurídicos, valga señalar, que si bien se trata de una situación particular, en virtud del vínculo que une a víctima y agresor, en realidad no se trata de una responsabilidad civil distinta. Como tampoco lo sería la responsabilidad civil por violencia de género.

16 De esta opinión Gómez ChíQuiza, M. E., intervención en Seminario de profesores sobre jurisprudencia constitucional. SU-080 de 2020, Universidad Externado de Colombia, Bogotá, 31 de marzo de 2020 . 
Es decir, la responsabilidad se debe declarar solo en aquellos casos en que se demuestre la existencia efectiva de un daño, el nexo de causalidad entre la lesión y el hecho dañino y el criterio de imputación. Ciertamente, en relación con el daño, en virtud del principio de reparación integral, se deberán reparar todos los daños, patrimoniales y no patrimoniales, que se demuestren por la lesión a la integridad psicofísica, incluido el pretium doloris ${ }^{17}$, "sin lugar a consideraciones sobre la compatibilidad o no de esta con otras medidas compensatorias previstas por el ordenamiento, pero no dirigidas a reparar el daño, pues ello estaría ligado a la carga ideológica de las discusiones que involucran a la familia ${ }^{18}$, pero no resuelve el problema concreto de la reparación del daño intrafamiliar" ${ }^{19}$. En fin, en este escenario es necesario que el jurista aumente la sensibilidad en relación con formas alternativas de reparación, como la petición de excusas o incluso formas que impliquen omisiones, por ejemplo, en casos en los que la víctima desee romper todo vínculo con el agresor.

Adicionalmente, el legislador debe asumir las violencias como un problema de salud pública. Al respecto es interesante notar que otro problema de salud pública que ha sido atendido recientemente por las autoridades, como la pandemia por Covid-19, ha arrojado datos alarmantes sobre las implicaciones de medidas como el aislamiento obligatorio para las víctimas del maltrato: mujeres, hijos, padres y abuelos ancianos, que se ven obligados al "encierro" con sus verdugos ${ }^{20}$. En ese sentido, la intervención del legislador no se puede detener en la previsión de mecanismos de reparación, que ya existen, o en la determinación de aspectos procesales, sino en atacar problemas estructurales para la efectividad de los derechos de las víctimas, por ejemplo: medidas de educación a los funcionarios que deben intervenir en estas situaciones, para evitar decisiones influenciadas por estereotipos de cualquier naturaleza; medidas que permitan a la víctima tener independencia del agresor o agresora, de manera que no esté obligada a mantener la relación por la imposibilidad de proveer a su sustento o al de otros miembros dependientes de la familia; medidas que permitan un acompañamiento al agresor o agresora, para determinar las reales causas de la violencia y hacerle frente, pues el problema no se puede reducir al puro y simple tentativo de dominación, o a la desviación del estándar de comportamiento, o a la enfermedad mental ${ }^{21}$.

17 Kотегсн, M., La reparación del daño como mecanismo de tutela de la persona del daño a la salud a los nuevos daños extrapatrimoniales, Universidad Externado de Colombia, Bogotá, 2012, pp. 256-259.

18 CoRTÉs, E., Responsabilidad civil y daños a la persona: el daño a la salud en la experiencia italiana, ¿un modelo para América Latina?, Universidad Externado de Colombia, Bogotá, 2009, 31.

19 RuEdA, N., "La violencia intrafamiliar como fuente de daño resarcible en Colombia", cit., 214.

20 Para ver la dimensión del problema, cfr. la nota de prensa de Ana María Montoya del 29 de marzo de 2020 [www.eltiempo.com/bogota/violencia-contra-la-mujer-en-tiempos-de-encierro-el-otro-desafio-de-bogota-478224], donde se señala que, según datos oficiales de la alcaldía de Bogotá, "en los primeros siete días [de aislamiento obligatorio], la Línea Púrpura, el canal habilitado para que las mujeres víctimas de violencia tengan orientación psicológica y jurídica, recibió 1336 llamadas y el WhatsApp Púrpura, que tiene el mismo fin, atendió 1.197 solicitudes”.

21 Cfr. Lifante Vidal, I., "Amor, dominación y Derecho. Una reflexión a propósito de Te doy mis ojos", InterseXiones, vol. 3, 2012, 2. 
En otras palabras, es esencial escuchar todas las voces que se pueden alzar en una situación de violencias, como la única garantía de aproximación integral al fenómeno.

\section{Referencias}

Albarracín Cogollo, A., "La reparación de los perjuicios ocasionados por el divorcio en la legislación colombiana", Temas Socio-Jurídicos, vol. 30 , n. ${ }^{\circ}$ 62, 2012, 195-206.

AriZA, A. "Morir de amor. Una mirada a las violencias afectivas desde un enfoque de cultura ciudadana", en Eslava, A. (ed.), Lo mejor de las personas. Teoría, intervención y agenda de la cultura ciudadana, Alcaldía de Medellín, Medellín, 2019, 103-122.

Beauvoir, S. DE., El segundo sexo, Ediciones Cátedra, Madrid, 13. a ed. en español, 2018.

Bourdieu, P., La domination masculine, Éditions du Seuil, Paris, 1998.

CORTÉs, E., Responsabilidad civil y daños a la persona: el daño a la salud en la experiencia italiana, ¿un modelo para América Latina?, Universidad Externado de Colombia, Bogotá, 2009.

Cruz del Castillo, C., "El amor romántico, los estereotipos de género y su relación con la violencia de pareja", Aportaciones a la psicología social, Iv, 2018, 459-474.

Feci, S. y Schettini, L., "Storia e uso pubblico della violenza contro le donne", en ID. (eds.), La violenza contro le donne nella storia: contesti, linguaggi, politiche del diritto (secoli $X V$-XXI), Storia delle donne e di genere; Plurale 8, Viella, Roma, 2017, 7-39.

FeCI, S. y Schettini, L. (eds.), La violenza contro le donne nella storia: contesti, linguaggi, politiche del diritto (secoli $\mathrm{XV}$-XXI), Storia delle donne e di genere; Plurale 8, Viella, Roma, 2017.

Gómez Chíquiza, M. E., "El resarcimiento de perjuicios causados en las relaciones de familia: una breve mirada desde la sociología y el derecho", Revista nuevos paradigmas de las ciencias sociales latinoamericanas, vol. 9 , n. ${ }^{\circ} 8$, disponible en [www.ilae.edu.co/Ilae_OjsRev/index.php/NPvol-vII-Nro14/article/view/277].

HAN, B-C., Topología de la violencia, Herder, Barcelona, 5. a reimp., 2018. 
Irigaray, L., Speculum. De l'autre femme, Les éditions de Minuit, Paris, 1974.

Котегсн, M., La reparación del daño como mecanismo de tutela de la persona del daño a la salud a los nuevos daños extrapatrimoniales, Universidad Externado de Colombia, Bogotá, 2012.

LifANTE VIDAL, I., “Amor, dominación y Derecho. Una reflexión a propósito de Te doy mis ojos", InterseXiones, vol. 3, 2012, 1-20.

Rescigno, P., “Immunità e privilegio”, Rivista di diritto civile, I, 1961, 415-445.

Rey Anacona, C. A. y Martínez Gómez, J. A., Violencia en el noviazgo. Evaluación, prevención e intervención de los malos tratos en parejas jóvenes, Manual Moderno, Bogotá, 2018.

RuEDA, N., La responsabilidad civil en el ejercicio de la parentalidad. Un estudio comparado entre Italia y Colombia, Universidad Externado de Colombia, Bogotá, 2020, en prensa.

RuEDA, N., "La violencia intrafamiliar como fuente de daño resarcible en Colombia", Revista de la Facultad de Derecho y Ciencias Políticas 48, n. ${ }^{\circ}$ 128, 2018 , 193-217.

Saldarriaga, D. C. y Álvarez Cadavid, N., Mujeres víctimas de violencia intrafamiliar. Implementación de la Ley 1257 de 2008, Unaula, Medellín, 2019.

SANDOval, D., "Reparación integral y responsabilidad civil: el concepto de reparación integral y su vigencia en los daños extrapatrimoniales a la persona como garantía de los derechos de las víctimas”, en Revista de Derecho Privado, Universidad Externado de Colombia, n. ${ }^{\circ}$ 25, 2013, 235-271.

\section{Jurisprudencia}

Corte Suprema de Justicia, cas. civ., 25 de julio de 2017, ref. STC 10829-2017.

Corte Suprema de Justicia, cas. lab., 27 de septiembre de 2017, rad. n. ${ }^{\circ} 75391$.

Corte Constitucional, SU-080 de 2020

Corte Constitucional, T-271 de 2016. 